\title{
Orthopnea in Obese Adult Patients: Can It Be Quantified From Lung Function Testing?
}

Obesity is an overwhelming public threat. It has been estimated that more than one third of the adult population is obese despite the fact that the prevalence has remained stable since $2004 .{ }^{1}$ The good news is that the prevalence of obesity has leveled off; the bad news is that the number remains high enough to pose a significant public concern with multiple health-related implications. With many of the obese adults getting older, it is very likely that an increasing number will be admitted to the hospital in the future. Obese patients present many clinical challenges in that they are more likely to develop sleep disordered breathing, diabetes mellitus, ischemic heart disease, hypertension, several different types of cancer, and gall bladder disease as well as potentially having a significant degree of respiratory compromise. ${ }^{2}$

In terms of respiratory compromise, obese patients experience a reduced expiratory reserve volume and a diminished functional residual capacity. ${ }^{3}$ In particular, a low functional residual capacity increases the risk of both expiratory flow limitation (EFL) and small airway closure. Thus, expiratory flow may be limited during tidal breathing in healthy obese individuals, and this may be even more pronounced when in the supine position. ${ }^{4}$ This is an important point because the basic physiologic principle in terms of functional residual capacity is that it should increase when a patient goes from the sitting to the supine position. However, physiologic changes occur in obese individuals that may be more profound in the supine position due to excess adipose tissue affecting the abdomen and chest wall. As a result of EFL and airway closure, there could be a ventilation/perfusion imbalance where some areas of the lungs might be underventilated and overperfused. Obese patients receiving mechanical ventilation are at even greater risk of deleterious effects because EFL promotes dynamic hyperinflation with a corresponding increase in the work of breathing to overcome the resultant intrinsic PEEP in the supine position. ${ }^{5}$

In this issue of Respiratory CARE, Perino et $\mathrm{al}^{6}$ sought to examine the role of closing volume as an indicator of

Mr Davies has disclosed no conflicts of interest.

Correspondence: John D Davies MA RRT FAARC, Box 3911, Duke University Hospital, Durham, NC 27710. E-mail: john.davies@ duke.edu.

DOI: $10.4187 /$ respcare. 05057 orthopnea in stable obese patients both in the sitting and supine position while, at the same time, looking at EFL.

See the Original Study on Page 1015

They hypothesized that an increase in closing volume in the supine position would be higher in orthopneic subjects as compared with non-orthopneic subjects and that the relationship of orthopnea to closing volume is related to the degree of EFL. Perino et $\mathrm{al}^{6}$ studied 21 stable, obese subjects, of whom 12 were considered orthopneic and 9 were not in terms of lung volumes, dyspnea, and EFL in the sitting and supine position. They found that there was no difference in lung function tests (including closing volume) between orthopneic and non-orthopneic subjects in the sitting position. Also, in orthopneic subjects, the closing volume did not change with changes in position (sitting to supine). However, non-orthopneic subjects experienced changes in the single-breath nitrogen washout consistent with a decrease in EFL in the supine position as compared with sitting. Finally, the group did find that the magnitude of orthopnea seemed to be related to the opening capacity and the presence of expiratory flow limitation. The presence and degree of EFL depends on the balance between expiratory flow reserve and ventilatory demand. Unfortunately, in obese individuals, expiratory flow reserve is decreased because of the lower expiratory reserve volume.

I applaud Perino et $\mathrm{al}^{6}$ for their efforts to quantify the degree of orthopnea and the effects of obesity on the pulmonary system. I believe their results highlight the complexity of the effects that obesity may have on the pulmonary system. As the authors pointed out, this was the first study examining the effects of obesity on the closing volume and, although their results were not conclusive in terms of closing volume, they did add to a growing body of knowledge relating to the effects of obesity. It is clear that obesity (more importantly, the degree of obesity) has multifactorial effects on lung function tests, and this makes interpretation difficult at times. However, it certainly appears that decreased expiratory lung volumes and expiratory flow limitation are 2 of the more important effects that obesity has on the pulmonary system.

In summary, the study by Perino et $\mathrm{al}^{6}$ adds more knowledge regarding the effects of obesity on the pulmonary system. It is clear that more work is needed in this area for 


\section{EDITORIALS}

clinicians to understand the effects of obesity and then be able employ appropriate therapeutic regimens. Clinicians may need to modify current practices in obese patients when the clinical goal is to improve resting lung volumes in sedentary patients.

John D Davies MA RRT FAARC

Respiratory Care Services

Duke University Hospital

Durham, North Carolina

\section{REFERENCES}

1. Ogden CL, Carroll MD, Kit BK, Flegal KM. Prevalence of childhood and adult obesity in the United States, 2011-2012 JAMA 2014;311(8): 806-814.
2. Mokdad AH, Marks JS, Stroup DF, Gerberding JL. Actual causes of death in the United States, 2000. JAMA 2004;291(10): 1238-1245.

3. Ray CS, Sue DY, Bray G, Hansen JE, Wasserman K. Effects of obesity on respiratory function. Am Rev Respir Dis 1983;128(3):501506.

4. Koutsoukou A, Koulouris N, Bekos B, Sotiropoulou C, Kosmas E, Papadima K, Roussos C. Expiratory flow limitation in morbidly obese postoperative mechanically ventilated patients. Acta Anaesthesiol Scand 2004;48(9):1080-1088.

5. Lemyze M, Mallat J, Duhamel A, Pepy F, Gasan G Barrailler S, et al. Effects of sitting position and applied positive end-expiratory pressure on respiratory mechanics of critically ill obese patients receiving mechanical ventilation. Crit Care Med 2013;41(11):2592-2599.

6. Perino E, Nesme P, Germain M, Guérin C. Mechanisms of orthopnea in stable obese subjects. Respir Care 2016;61(8):1015-1022. 